\title{
EPISTEMOPOLÍTICAS DO DISPOSITIVO CARCERÁRIO PAULISTA: refletindo sobre experiências de pesquisa-intervenção junto à Pastoral Carcerária
}

\author{
Rafael Godoi \\ Marcelo da Silveira Campos² \\ Fábio Mallart ${ }^{3}$ \\ Ricardo Campello4
}

\section{Palavras-Chave \\ prisão, metodologia, epistemologia, política, São Paulo}

\section{SUMÁRIO}

1. Introdução. 1.1 Atuar na Pastoral. 1.2 Pesquisa a prisão. 2. Epistemopolíticas. 2.1 Questões epistemológicas. 2.2 Questões políticas. 3. Pesquisa-intervenção. 3.1 Nos subterrâneos. 3.2 Nas superfícies. 3.3 Nos cumes. 4. Considerações finais. 5. Referências.

'Pesquisador de pós-doutorado do Programa de Pós-Graduação em Sociologia e Antropologia (PPGSA) e do Núcleo de Estudos da Cidadania, Conflito e Violência Urbana da UFRJ. Doutor em sociologia pela USP. Autor de "Fluxos em cadeia: as prisões em São Paulo na virada dos tempo" (Boitempo) e organizador de "BR 111: a rota das prisões brasileiras" (Veneta/Le Monde Diplomatique Brasil).

2Pós Doutorando no INCT-InEAC/UFF, professor adjunto da UFGD professor convidado da Faculdade de Medicina da USP, doutor em sociologia pela USP. Autor de "Pela Metade: a lei de drogas do Brasil" (Annablume).

${ }_{3}$ Mestre em Antropologia e doutor em Sociologia pela Universidade de São Paulo (USP). Atualmente, é pesquisador de pós-doutorado pelo Instituto de Medicina Social da Universidade do Estado do Rio de Janeiro (IMS/UERJ). Autor de "Cadeias dominadas: a Fundação CASA suas dinâmicas e as trajetórias de jovens internos" (Terceiro Nome/ Fapesp) e organizador de "BR 111: a rota das prisões brasileiras" (Veneta/Le Monde Diplomatique Brasil)

${ }^{4}$ Mestre em Ciências Sociais pela Pontifícia Universidade Católica de São Paulo e doutor em Sociologia pela Universidade de São Paulo.

\section{Resumo}

O artigo tem por objetivo refletir sobre as potencialidades críticas e heurísticas da pesquisa sociológica sobre o dispositivo carcerário paulista, levada a cabo através do engajamento dos pesquisadores em coletivos e atividades da Pastoral Carcerária. As dimensões astronômicas do sistema carcerário paulista ; sua notável centralidade nos mecanismos de gestão do conflito que garantem a (re)produção da cidade contemporânea ; bem como as várias dificuldades impostas pela administração penitenciária no local ao escrutínio público do ambiente carcerário em geral, e à prática da pesquisa científica em particular, são as principais justificativas para esta reflexão. No decorrer do texto, os sentidos práticos e analíticos da atuação de diferentes pesquisadores/agentes pastorais são expostos e discutidos através de uma metáfora geológica, indagando sobre as características e limites da atuação e do conhecimento que se desdobram nos subterrâneos, na superfície e no cume do sistema carcerário. 


\title{
EPISTEMOPOLITICS OF THE SÃO PAULO PRISON APPARATUS: reflecting on research-intervention experiences with the Pastoral Carcerária.
}

\author{
Rafael Godoi \\ Marcelo da Silveira Campos \\ Fábio Mallart \\ Ricardo Campello
}

Keywords

prison, methodology, epistemology, politics, São Paulo

\section{Abstract}

The article aims to reflect on the critical and heuristic potential of sociological research on the São Paulo prison system, carried out through the engagement of researchers in collectives and activities of Pastoral Carcerária. The astronomical dimensions of the São Paulo prison system; its remarkable centrality in the conflict management mechanisms that guarantee the (re) production of the contemporary city; as well as the various difficulties imposed by the prison administration on public scrutiny of the prison environment in general, and the practice of scientific research in particular, are the main justifications for this reflection. Throughout the text, the practical and analytical meanings of the work of different researchers / pastoral agents are exposed and discussed through a geological metaphor, asking about the characteristics and limits of the practices and knowledge that unfold in the underground, on the surface and at the top of the prison system. 


\section{INTRODUÇÃO}

Neste texto procuramos refletir sobre as potencialidades críticas e heurísticas da pesquisa sociológica sobre o sistema prisional paulista, levada a cabo através do engajamento dos pesquisadores em coletivos e de atividades da Pastoral Carcerária. A partir do relato de experiências de pesquisa e de intervenção, trata-se de definir e elaborar as dimensões epistemológicas e políticas de saberes que se desdobram de uma posição parcial e situada, bem como de circulações específicas pelas tramas do dispositivo carcerário.

As principais justificativas para essa reflexão passam pelas dimensões astronômicas do sistema penitenciário estadual com 240.061 presos (DEPEN, 2016), pela sua notável centralidade nos mecanismos de gestão do conflito que garantem a (re)produção da cidade contemporânea (Minhoto, 2015) e pelas inúmeras dificuldades impostas pela administração penitenciária local ao escrutínio público do ambiente carcerário em geral e à prática da pesquisa científica em particular. Na base dessa reflexão, figura uma inquietação quanto ao estatuto do saber que se produz a partir dessa zona de indiscernibilidade entre pesquisa e intervenção; no horizonte, almeja-se a compreensão de que tal exercício é central para a ampliação das possibilidades de análise, crítica e desconstrução das atuais formas de punição no Brasil contemporâneo.

Nestas linhas, nosso principal objetivo é refletir sobre as potencialidades e as tensões que experimentamos em iniciativas diversas de pesquisa-intervenção junto à Pastoral Carcerária. Aqui, portanto, não expomos exatamente os resultados de uma pesquisa em particular, mas sim os resultados de um diálogo entre pesquisadores, com projetos e perspectivas distintas, mas similares inserções no dispositivo carcerário paulista e, principalmente, similares disposições para refletir sobre as dimensões políticas da produção do saber e sobre as possibilidades cognitivas do engajamento político. Trata-se, em suma, de uma reflexão epistemológica e metodológica de caráter necessariamente exploratório (Stebbins, 2001; Reiter, 2017).

\subsection{Atuar na Pastoral}

Ligada à Igreja Católica e à Confederação Nacional dos Bispos do Brasil (CNBB), a Pastoral Carcerária, atualmente, possui cerca de 6.000 integrantes espalhados pelo país. Seus agentes visitam presídios e cadeias públicas com o objetivo de prestar assistência religiosa, bem como de defender os direitos de cidadania das pessoas presas. "Estive preso e vieste me visitar" (Mt 25, 36) é uma das frases centrais que resume a experiência Pastoral para os agentes e para os detentos. Como se constata no website da organização (carceraria.org.br), tal instituição se autodefine como "a presença de Cristo e de sua Igreja no mundo dos cárceres", e se autocaracteriza como uma organização que:

1) Está junto das pessoas privadas de liberdade (...). 2) Busca a Libertação integral (...). 3) Luta para cancelar toda legislação e normas contrárias à dignidade e aos direitos fundamentais às pessoas privadas de liberdade(...). 4) Respeita a dignidade da pessoa humana (...) sem preconceito nem discriminação, acolhendo, perdoando, recuperando a vida e a liberdade de cada um, denunciando os desrespeitos à dignidade humana e considerando as condições materiais, históricas, sociais e culturais em que cada pessoa vive. 
Tais princípios norteadores se concretizam em uma ampla diversidade de práticas, variáveis conforme as circunstâncias, as unidades prisionais visitadas e os agentes pastorais envolvidos. Sem exceção, fomos socializados na atividade pastoral numa interação estreita com agentes pastorais combativos e politizados, em diálogo direto com o corpo diretivo da entidade, sem maiores questionamentos sobre nossas convicções religiosas - uma vez que nem todos se aproximam da fé católica. Não obstante tal entrada comum, cada um de nós foi desenvolvendo uma trajetória singular no interior da organização, que redundou em atividades e experiências muito diversas - que servem agora de matéria-prima para esta reflexão conjunta. Tal diversidade de experiências leva a uma série de impressões. Dentre as que aqui não serão trabalhadas, gostaríamos de mencionar uma particularmente instigante. A condição de agente pastoral não apenas viabiliza a entrada na prisão, mas modifica nossa visão de mundo, alterando o modo de observar as interações cotidianas na cidade e de circular pelo território aberto. O pesquisador segue sendo agente pastoral nas imediações da Praça da Sé, na "cracolândia", na periferia da cidade, ou mesmo num município do interior durante o final de semana. Essa marcação não serve apenas para assinalar o impacto subjetivo da experiência de visitação prisional mas, sobretudo, para indicar o quanto, para quem conhece as agruras da prisão, seus sinais se fazem presentes o tempo todo e em todo lugar.

\subsection{Pesquisar a prisão}

Desde 2010, o cientista social interessado em melhor compreender o sistema prisional paulista em qualquer uma de suas dimensões deve, em tese, submeter o seu projeto de pesquisa ao Comitê de Ética em Pesquisa (CEP) da Secretaria de Administração Penitenciária (SAP, 2017), que funciona por meio da Plataforma Brasil de pesquisa com seres humanos - sendo, portanto, também estruturado a partir dos imperativos éticos da pesquisa médica. Consideramos inadequado esse enquadramento proposto pelo CEP a toda e qualquer pesquisa e, nesse ponto, fazemos coro com diversos cientistas sociais que há algum tempo vêm se mobilizando pela institucionalização de parâmetros éticos e mecanismos de regulação que sejam adequados à pesquisa em ciências humanas e sociais (cf. ANPOCS, 2011). A Resolução 510 do Conselho Nacional de Saúde (CNS), de 7 abril de 2016, atesta o avanço no reconhecimento institucional dessas especificidades (MS, 2016), mas seus efeitos práticos ainda não podem ser dimensionados.

De todo modo, tal como vem operando nos últimos anos, o comitê de ética, ao invés de viabilizar pesquisas em ciências humanas, parece mais impor sérias dificuldades para sua realização, constituindo-se como mais uma peça destinada à regulação daqueles que almejam conhecer o que se passa no interior da máquina carcerária. Massaro (2014, p. 36), por exemplo, relata a demora na apreciação de seu pedido e as múltiplas exigências burocráticas às quais teve de se submeter para realizar entrevistas com internas de um Centro de Ressocialização (CR) do interior.

Vale ressaltar que os bloqueios que se impõem à pesquisa acadêmica nas prisões não são uma novidade trazida pela instauração do CEP, nem uma particularidade do estado de São Paulo. No decorrer da história, o grau de abertura das prisões ao escrutínio 
de agentes que Ihes são externos varia bastante: do suplício ao encarceramento, verifica-se a transição para uma modalidade de punição mais discreta (Foucault, 1999), ainda que as primeiras instituições prisionais tenham sido frequentemente visitadas por especialistas e até pelo público (cf. Rothman, 2008). Recentemente, uma maior abertura se converte em questão candente, tornando-se objeto de políticas deliberadas em diferentes contextos (Barak-Glantz, 1981; Combessie, 1996) e conjunturas (Coelho, 2005; Lemgruber e Paiva, 2010).

A instauração de regimes de visibilidade (Deleuze, 1987), o controle da informação e a manipulação do segredo (Senellart, 2006) são expedientes inerentes ao exercício do poder - inclusive o de punir. Por isso, entrar na prisão para realizar estudos de natureza sociológica invariavelmente implica alguma dificuldade, que pode ser contornada de variadas maneiras. Pesquisadores desenvolvem seus trabalhos ou cumprindo as exigências burocráticas estabelecidas (Chantraine, 2004a; Massaro, 2014; Fassin, 2015), ou através de autorizações específicas da administração prisional (Ramalho, 2002; Dias, 2013; Diniz, 2015), ou na qualidade de visitantes de pessoas encarceradas (Ricordeau, 2007; Biondi, 2010), ou a partir de sua própria inserção profissional nos espaços de reclusão (Castro e Silva, 2011; Mallart, 2014; Melo, 2014). Nessa chave, a inserção via Pastoral Carcerária, para além de suas próprias potencialidades e limitações, é apenas mais uma das possibilidades de acesso (Lago, 2014; Godoi, 2017; Zamboni, 2017; Antunes, 2017; entre outros).

\section{EPISTEMOPOLÍTICAS}

Embora a inquietação quanto à objetivi- dade do conhecimento sociológico se faça presente no decorrer de todo o processo de desenvolvimento dessa ciência, desde os autores clássicos até as principais referências da produção contemporânea, será impossível percorrer aqui todo esse debate. Limitamo-nos, portanto, a evocar algumas referências que nos são particularmente caras para, em seguida, aprofundar a reflexão sobre como essa questão emerge, especificamente, no campo dos estudos prisionais.

\subsection{Questões epistemológicas}

Encontramos em Fassin (2009) uma reflexão detida e atual acerca dos dilemas postos pela participação do pesquisador nas dinâmicas sociais que estuda, no que diz respeito à objetividade do conhecimento produzido. O autor mobiliza como metáfora a alegoria da caverna de Platão: dentro dela, o mundo dos sujeitos estudados, com suas práticas e valores; fora, o universo do conhecimento, da verdade e da objetividade. O cientista social, segundo Fassin, é aquele que se situa no limiar desses dois mundos. Em suas palavras:

Le chercheur en sciences sociales ne se situe ni en dedans, ni au-dehors de la caverne, mais bien, de fait, sur le seuil et tout son travail précisément scientifique consiste à prendre la mesure de cette position. Étant ainsi sur le seuil de la caverne, il peut sans cesse passer d'un côté et de l'autre. C'est une autre façon de dire qu'il est toujours dans cette tension entre engagement et distanciation, (...) il fait partie de ce monde qu'il étudie et y est donc engagé, tout en travaillant à le constituer en objet, par conséquent en s'en distanciant. La plus haute exigence de la pensée critique est de se situer sur 
cette ligne de crête : au confort - relatif - de l'alternative entre dénonciation et description, l'exercice critique des sciences sociales consiste em ces allers et retours où, lorsqu'on est proche des sujets avec lesquels on travaille, on est attentif à leurs discours et leurs pratiques (...) et lorsqu'on s'éloigne d'eux pour saisir une scène sociale plus vaste, on devient plus sensible aux jeux de pouvoir dans lesquels ils acceptent de se laisser prendre au point de porter sur eux un regard sans concession. (Fassin, 2009, pp. 201-202)

Diante dessas considerações, é preciso reter três elementos. Em primeiro lugar, a condição necessariamente liminar do cientista social. A partir de tal entendimento, compreende-se que as tensões experimentadas como pesquisadores e agentes da Pastoral Carcerária - tensões que se apresentam de forma particularmente aguda - não nos são específicas, mas sim, constitutivas do próprio labor sociológico. Em segundo lugar, a ponderação de que essa liminaridade implica uma contínua circulação, isto é, movimentos sucessivos de aproximação e de distanciamento da organização ou do movimento social em questão, mas também momentos de imersão científico-politica. $O$ limiar, mais do que uma posição fixa, é uma concatenação de posicionamentos no universo das práticas e da crítica - concepção que permite apreender e elaborar os nexos e disjunções que se estabelecem entre as nossas práticas de intervenção e os discursos analíticos formulados. Finalmente, destaca-se o caráter necessariamente crítico da objetividade científica, que articula um saber rigoroso acerca do mundo social a partir de uma abordagem dos jogos de poder amplificados, os quais estruturam esse mundo e impõem uma apreciação sem concessões de seus elementos e dinâmicas.

De nossa parte, sem deixar de reter esses entendimentos, nos distanciamos da metáfora da caverna, já que entendemos que o mundo das práticas não se separa do mundo da verdade objetiva (Foucault, 1996). Como diz Haraway (1988), qualquer objetividade só é possível a partir de um corpo situado, de uma perspectiva parcial. O limiar entre dois mundos de Fassin se converte então num posto de observação em um só e mesmo mundo, um corpo e um lugar que precisam ser qualificados, como condição básica para se garantir a desejada objetividade. A metáfora de Haraway é a dos instrumentos óticos, cada qual com suas propriedades e potencialidades específicas que possibilitam a observação objetiva de dimensões diversas da realidade.

A pesquisa prisional é particularmente fecunda para a constatação da validade de tais asserções. Como a prisão é um espaço social repleto de hierarquias, barreiras e conflitos, cada entrada específica possibilita a objetivação de determinadas estruturas e dinâmicas, enquanto turva outras. $O$ que se observa na sala do diretor de disciplina não pode ser o que se verifica na cela num dia de visita, que também difere do que se vê na mesma cela numa visita pastoral; nenhuma dessas posições qualificadas garante um acesso privilegiado à "verdade" da prisão, mas todas elas possibilitam a observação objetiva de determinados aspectos da produção dessa realidade complexa. Em linhas gerais, a entrada pastoral engendra duas limitações: de um lado, tende a inspirar certa desconfiança e frieza nos funcionários; de outro, quanto aos presos, há uma diretriz da entidade para que seus agentes procurem ignorar o que cada um fez (ou foi acusado 
de fazer) para estar na prisão, também sobre o que fazem (ou pretendem fazer) de ilegalismos vários, dentro e fora da instituição - diretriz que procura evitar discriminações no atendimento pastoral. Portanto, a posição de agente pastoral não favorece investimentos na análise do mundo social do funcionalismo penitenciário ou do crime ainda que estes sejam, eventualmente, possíveis. Entretanto, a presença continuada no interior da prisão, o acesso aos seus espaços e o diálogo com detentos e funcionários possibilitam conhecer certas dinâmicas de funcionamento, bem como traços estruturantes da experiência da punição.

Como ressalta Haraway (1988), tão importante quanto bem calibrar o discurso sobre o que se vê a partir das qualidades e das limitações dos instrumentos de que se dispõe - do corpo que se tem, do lugar que se ocupa, etc. - é a arte de combinar instrumentos, de mudar de posição. A necessária circulação do pesquisador adquire então um outro sentido, ainda mais radical: já não se trata apenas de intercalar expedientes de pesquisa empírica e momentos de reflexão, mas de transitar por outras searas do mundo social que se estuda, bem como de construir e ocupar outros postos de observação. A iniciativa de construir a muitas mãos o presente texto visa também a experiência de compor perspectivas e multiplicar deslocamentos.

\subsection{Questões políticas}

As implicações políticas e cognitivas de posicionamentos práticos e analíticos são particularmente decisivas no campo dos estudos prisionais. Segundo Chantraine (2004b), historicamente, a sociologia da prisão vem se estruturando sobre um dilema que opõe o reconhecimento da necessidade urgente de reformas à rejeição, absoluta e por princípio, da instituição - ou seja, entre a reforma e a abolição. De um lado, estrutura-se um saber que alinha a análise científica aos objetivos pedagógicos da instituição. Ora, como ressalta Foucault (1999), a crítica reformadora é contemporânea do próprio processo de implantação dos sistemas penitenciários modernos - ela funciona como seu programa. Repetidos há duzentos anos, os mesmos argumentos seguem informando análises contemporâneas. Ao reafirmarem o projeto correcionalista, naturalizam a "realidade" do encarceramento e, por isso mesmo, se aproximam do discurso tecnocrático administrativo da instituição, aperfeiçoando-o. De outro lado, estrutura-se um saber que procura se destacar desse programa reformador, abrindo novos horizontes para a análise, mas que, ao mesmo tempo, pode negligenciar a situação concreta das pessoas presas pois coloca a abolição como único prospecto sócio-histórico concebível.

Para escapar desse dilema, Chantraine propõe o que ele chama de uma análise crítica descentrada, que procura perseguir as relações entre técnicas de governo e mecanismos de poder operantes dentro e fora da instituição - donde o descentramento. Tal postura é marcada pela tensão que se experimenta ao se opor à axiomática do discurso reformador, ao mesmo tempo em que se procura reter seu detalhismo empírico; também quando busca evadir-se das reduções abstratas de um abolicionismo teórico, mas ainda preservar a sua visão sistêmica. Conforme Chantraine (2004b), tais balizas podem contribuir para a produção de um saber sociológico acerca da prisão que busque desestabilizar o presente e desconstruir tecnologias de poder. 
A nosso ver, é possível afirmar que a tensão estabelecida entre uma maior atenção às necessidades concretas e imediatas dos presos e a luta antiprisional está inscrita na própria atuação da Pastoral Carcerária, que busca atender às necessidades imediatas de pessoas privadas de liberdade e que, cada vez mais, vem explicitando e difundindo o abolicionismo (cf. várias organizações, 2014). Pesquisadores e agentes pastorais debatem entre si cotidianamente a fim de encontrar meios que viabilizem um bloqueio às práticas penais e carcerárias correntes, sem desconsiderar premências e necessidades básicas de presos e presas, bem como as de seus familiares.

\section{PESQUISA-INTERVENÇÃO}

Feitas tais considerações de caráter mais geral, nas linhas seguintes trata-se de enfatizar as dimensões específicas de experiências que indicam as potencialidades e tensões da pesquisa-intervenção junto à Pastoral Carcerária. Cabe esclarecer, desde já, que essas são formulações exploratórias, de modo que, para tanto, lançamos mão de uma metáfora geológica. Trataremos de expor e discutir os sentidos práticos e analíticos de nossa atuação em três camadas ou escalas do mundo prisional: o subterrâneo, a superfície e o cume. Ressaltamos que cada um de nós privilegia a atuação e análise em um desses níveis, mas que todos eles, em alguma medida, estão presentes em nossas experiências e trajetórias. Ao expor cada um deles, procuraremos delimitar a função analítica e o horizonte de ação que tende a prevalecer, isto é, o que fazemos em nossos escritos e com nossos corpos.

3.1 Nos subterrâneos

São Paulo, 8 de maio de 2016

\section{Chácara Belém I}

Ao Gabinete do Governador do Estado.

Prezado Sr. Governador Geraldo Alckmin,

Eu, reeducando Pedro5, Matrícula XXX, cela 09, Seguro, venho por meio desta solicitar minha transferência urgente dessa unidade. Sou autor das denúncias sobre a casa: Relato NNN-NNN. Desde que fiz a denúncia fui várias vezes espancado por funcionários e estou sem banho de sol já faz mais de quatro meses. Os agentes me deixam trancado na cela desde janeiro e tenho sofrido várias perseguições. A diretoria não me dá atenção e a unidade colocou os próprios presos contra mim. Quando chega alguém das autoridades aqui na casa eles não chamam quem tem que chamar. Eu queria que o Sr. pudesse reconhecer o meu sofrimento nesse lugar e me transferisse daqui, ou me colocasse em um local separado de todos os presos. Não tenho família nenhuma em São Paulo, só tenho minha tia. Minhas correspondências vão tudo pro endereço dela. Desde já, agradeço ao Sr. sabendo que poderei receber a vossa atenção.

É do fundo do corredor do seguro que murmura a voz de Pedro. Pela pequena portinhola da porta da cela é possível observar as suas costas, braços e pernas já dominados pela evolução de irritações dérmicas causadas pela ausência de contato com o sol. De olhos bem abertos, Pedro suplica em sus-

${ }^{5 T o d o s}$ os nomes são fictícios. EPISTEMOPOLITICAS DO DISPOSITIVO CARCERÁRIO PAULISTA: refletindo sobre experiências de pesquisaintervenção junto à Pastoral Carcerária 
surros pelo encaminhamento de sua carta ao Governador do Estado. Na cela ao lado, Rubens informa que não recebe os medicamentos dos quais necessita desde que obteve resultado positivo de seu exame de HIV. Pede algum contato com o médico da unidade para solicitar seu coquetel. Um outro rapaz, recém-operado de um câncer no estômago, está impossibilitado de retirar os exames que indicarão a quantidade de sessões de quimioterapia necessárias ao tratamento. Não foi entregue a João a bolsa de colostomia para a coleta de suas fezes, após a retirada de um tumor colorretal.

Como agente da Pastoral Carcerária - e não sem dificuldades - tem-se acesso aos diversos espaços das prisões, mesmo porque essa é uma prerrogativa dos agentes, incluindo espaços subterrâneos como os castigos e os seguros, que dificilmente são acessados a partir de outra inserção. Os seguros são espaços institucionais mantidos fora dos pavilhões, sendo estes, por sua vez, conhecidos como convívio. Ao mesmo tempo, a categoria seguro remete aos presos e às presas que cometeram atos considerados inaceitáveis por seus companheiros de detenção, tais como estupro, caguetagem e desrespeito às visitas. Por sua vez, os castigos são corredores em geral estreitos e localizados perto dos seguros, com uma série de celas enfileiradas, bem menores do que as encontradas nos pavilhões, onde são trancados, geralmente por até 30 dias, presos e presas que estão em cumprimento de sanção disciplinar. Em cada uma das celas, que na maioria das unidades não passam de 15 , há uma cama de concreto, um cano que desempenha a função de chuveiro e um buraco no chão que opera como vaso sanitário. Em geral, tais locais são os mais fétidos, escuros e úmidos, com infiltrações por todos os lados, verdadeiros espaços subterrâneos da prisão.

Ao frequentar tais espaços, é possível experimentar o que Primo Levi define como "a vergonha de ser um homem". Vergonha composta, vergonha duplicada: de um lado, vergonha de que homens possam produzir e conduzir tal estado de coisas; de outro, vergonha por não poder impedí-lo, ou podê-lo muito limitadamente. No que se refere à prática pastoral, diante desses espaços, o maior ímpeto é o de remover seus habitantes, reivindicando junto à administração da unidade transferências para outras alas ou unidades - o que se prova quase sempre impossível. No mais das vezes, nos limitamos em providenciar algum suporte material - um cobertor, um sabonete, um medicamento - ou em avisar familiares e amigos do paradeiro do recluso - já que presos castigados não podem receber visitas. Contribuímos assim para poupar valiosos recursos que seriam gastos em deslocamentos e "jumbos" inúteis.

De um ponto de vista analítico, isto é, daquilo que se pode escrever sobre o que nesses espaços subterrâneos se vê, talvez a nossa maior contribuição possa ser aquela do testemunho, nos termos propostos por Agamben (2008). Diante do horror, resta testemunhar, documentar e denunciar sua existência. Nessa operação, procura-se trazer à luz o que as instituições punitivas fazem questão de soterrar. A tensão fundamental implicada nesse tipo de operação, também discutida por Agamben (ibid.), reside na aporia que se estabelece entre a urgência e a impossibilidade. Ao mesmo tempo em que se impõe a necessidade de relatar pormenorizadamente as circunstâncias que constituem esses espaços de multiplicação da dor e do sofrimento, sabe-se que a mais 
minuciosa descrição jamais poderá atingir o sentido pleno da experiência que eles produzem. Ainda que uma grande distância separe os campos, dos quais nos fala Agamben, das celas e corredores subterrâneos os quais visitamos, algo da insensatez e do escândalo dos primeiros reverbera nos segundos, invocando a função testemunhal.

\subsection{Nas superfícies}

Franco da Rocha, 2 de julho de 2012.

Raio 2. Primeiro, fiquei de canto conversando com alguns conhecidos. Depois, fui chamado para ver o corpo do Sérgio, caso de saúde gravíssimo: doente de não sei o quê, foi para a enfermaria e tomou duas injeções, que ou provocaram um tipo de reação alérgica, ou entraram em "conflito" no corpo do rapaz; o resultado foi uma necrose dos tecidos horrivel; ficou 6 meses internado no COC e voltou repleto de escoriações e cicatrizes mal fechadas no corpo todo. Mal podia olhar para ele. Depois fui procurado por: 1 - Welinton, negro, 18 anos, mais de um ano na fundação Casa, saiu de LA e fugiu, foi preso num outro $B O$ e por isso encaminhado para a prisão dos adultos, completou 18 anos fugido, não tem e não quer contato com a mãe, não recebe visita. Pediu papel higiênico e pasta de dente. 2 - Lindomar, uns 40 anos, pediu que ligasse para a esposa - de quem ele não mais "quer saber nada" - para retomar contato com a filha que aniversaria agora em fevereiro; sua demanda é receber cartas da filha, anotei o telefone da mãe e fiquei de providenciar o contato. 3 - Depois fui procurado por um rapaz de uns 40 anos também, branco, cabelos brancos, óculos quebrado, que se apresentou como Ciro (eu acho) e trouxe Ariosvaldo, um senhor de 65 anos, branco, magro. Ciro é recursista e precisa do número da apelação e de um extrato para fazer um recurso e pedir a liberação do senhor, que tem lapso vencido para 2 benefícios e não teve ainda nenhum encaminhado. O recursista era muito falante e articulado, falava efusivamente sobre a advogada da FUNAP que trabaIha na unidade, que, segundo ele, "não faz nada direito", não instrui os pedidos devidamente, mandando pedidos de benefícios sem a documentação necessária ("atestado" de bom comportamento, ou boletim com dias trabalhados, etc.), o que obriga o juiz a pedir novos documentos antes de decidir; disse ainda que a mesma advogada fala para os presos que encaminhou pedidos de benefícios, mas quando nós levamos os extratos os presos descobrem que os seus processos estão ainda em outra comarca. Esse é o caso de 4 - Emerson, cuja execução está em Francisco Morato (fiquei de ver esse caso e estimular a transferência do processo) (excerto de caderno de campo).

A superfície remete aqui aos espaços do convívio, no interior de pavilhões, e aos raios onde habita o maior número de presos, e onde se desdobram a maior parte das interações entre presos e agentes pastorais. Na superfície, a dimensão populacional da massa carcerária ganha relevo: nela nos deparamos com centenas e centenas de presos e presas, cumprindo as suas penas ou aguardando julgamento sob circunstâncias que poderiam se qualificadas como "normais", não fossem tão degradantes como são.

Nesses espaços, além das atividades próprias da assistência religiosa - leituras bí- 
blicas, celebrações, orações - os agentes da Pastoral Carcerária procuram estar sempre abertos às demandas dos presos, ajudando no que for possível. Expedientes de assistência material e jurídica compõem o repertório de práticas cotidianas: levamos livros, revistas e jornais para ajudar a passar o tempo; materiais para artesanato; papel higiênico, pasta de dente, sabonete para aqueles que não recebem visita; também providenciamos óculos, medicamentos, fraldas geriátricas, cadeiras de rodas, bombinhas para asma, drenos e bolsas de drenagem (de pus, de urina) para presos enfermos. Esclarecimentos sobre processos criminais, de execução penal e de apelação, bem como intervenções junto aos operadores do direito são, de longe, as demandas mais frequentes do maior número de presos, de modo que atividades ligadas à assistência jurídica ocupam uma posição central dentre as práticas pastorais: emitimos extratos da Vara de Execuções Criminais, tentamos decifrá-los, coligimos demandas específicas e as encaminhamos para a Defensoria Pública.

Atreladas a essas atividades rotineiras, alguns de nós desenvolvem projetos e ministram oficinas no interior do cárcere, em espaços que não deixam de compor o que estamos designando como superfície. Nessas ocasiões, ao se restringir o número de interlocutores possíveis e ao se propor mais ativamente uma pauta para o diálogo, é possível deixar o terreno das urgências e abrir a possibilidade de uma reflexão e uma troca sobre outras dimensões da experiência carcerária pregressa.

Seja a partir de uma visita ordinária a um raio, ou de um encontro em uma oficina de leitura, na superfície, a função analítica que prevalece é a cartográfica, tal como a propõe Foucault (cf. Deleuze, 1987). Numa car- tografia, não se almeja objetivar a subjetividade dos sujeitos, não se quer deslindar os sentidos atribuídos à experiência, nem perscrutar os valores e as crenças de uma dada coletividade. Nela, o que se objetiva é assinalar tropos, esboçar relevos, identificar regiões e suas vias de comunicação. As informações levantadas na superfície falam mais da prisão e do sistema do que dos presos ao assinalarem dinâmicas de funcionamento, lógicas de operação e circuitos de encaminhamentos. Pelo tipo de demandas que são postas na superfície, nela nos deparamos com a logística do sistema, forjada na empiria do cotidiano e das circunstâncias contingentes - inapreensíveis nos manuais, nos discursos oficiais, nas cartas legais e nas portarias administrativas. Da sucessão de casos individuais, sempre muito parecidos, mas irredutíveis entre si, podemos documentar as formas de gestão de destinos individuais e coletivos, e ver a prisão funcionando como aparato de gestão de populações.

A tensão constitutiva dessa modalidade de intervenção e análise não é menos desconcertante do que aquela que se experimenta no subterrâneo. Adentrar a prisão é estar necessariamente implicado com pessoas e suas urgências. É ser interpelado por questões das quais um descuido ou omissão produz um cúmplice. É penetrar o interior de uma máquina e pouco a pouco, quase sem perceber, fazer parte dela. Seja levantando andamentos processuais ou acionando o ambulatório da unidade, seja contatando a Defensoria Pública, ou ainda pressionando a direção da unidade para garantir o acesso de visitas. De tudo isso depreende-se a desconfortável sensação de estar sempre na iminência de cumprir funções de manutenção da máquina. Se o cárcere é hoje um dispositivo concebido e administrado não 
somente pelo Estado, mas por uma multiplicidade de agências e de agentes, configurando o que se poderia chamar de uma gestão compartilhada da delinquência, infiltrar-se em seus muros e atentar para a agonia dos que ali habitam resvala sempre no risco de assumir o indesejável papel de co-gestor.

\subsection{Nos cumes}

Cabe registrar, por fim, ainda no campo das alternativas à criminalização, que a própria Lei 11.343/2006 contém interessantes diretivas que muito podem contribuir para resultados mais eficazes no combate às drogas, em relação a usuários e dependentes, do que a criminalização da posse para uso pessoal. Sobre - tema, ponderam Marcelo Campos e Rodolfo Valente (Boletim, IBCCRIM, outubro/2012, p. 3), verbis:[...] de fato, há outros meios alternativos à criminalização, adequados aos fins propostos. A própria lei 11.343/60 traz profícuas diretrizes que, antagonicamente, são tolhidas pela política repressiva [...]. Todas as diretrizes são encadeadas em articulação necessária com os princípios e diretrizes do Sistema Único de Saúde e da Política Nacional de Assistência Social e norteadas pelo fortalecimento da autonomia e da responsabilidade individual em relação ao uso indevido de drogas (art. 19, III). (excerto da justificativa de voto do Ministro do STF Gilmar Mendes sobre o Recurso Extraordinário n 635.659 - íntegra disponível em 19 https://jota.info/especiais/drogas-a-integra-do-voto-doministro-gilmar-mendes-20082015)

Em 25 de maio de 2012, a equipe do Projeto Justiça Criminal/Brasília da Pastoral Car- cerária protocolou o $\mathrm{AMICI}$ CURIAE sobre o Recurso Extraordinário n 635.659. Tal recurso, atualmente aguardando julgamento no Supremo Tribunal Federal com três votos favoráveis à descriminalização das drogas, foi interposto pelo Defensor Público Geral do Estado de São Paulo contra o Ministério Público do Estado de São Paulo e com Repercussão Geral reconhecida em 09 de dezembro de 2011, que discute e questiona a constitucionalidade do artigo 28 da Lei $n^{\circ}$ 11.343/2006. Em proveito desse pedido de ingresso da Defensoria acima citado, as entidades signatárias protocolaram o Amicus reputando o artigo 28 da Lei $n^{\circ} 11.343 / 2006$, o qual criminaliza o uso de drogas, julgando-o também como inconstitucional. No entendimento do Supremo Tribunal Federal, essa possibilidade de manifestação da sociedade civil nesse tipo de processo tem o fito de democratizar o controle de constitucionalidade, oferecendo novos elementos para os julgamentos. E foi assim que, além de protocolar em Brasília o Amicus Curiae, na época, o projeto promoveu visitas diretas aos ministros do STF para discutir o recurso. Além disso, a equipe do projeto elaborou juntamente com o IBCCrim um Boletim Especial sobre Drogas, incluindo um caderno sobre jurisprudência nas políticas de drogas em diferentes países (Brasil, Argentina, Colômbia e Alemanha). O primeiro artigo deste boletim (Campos e Valente, 2012) é o que foi citado diretamente na justificativa do voto do Ministro do STF Gilmar Mendes, favorável à descriminalização do uso de drogas no Brasil.

As circunstâncias descritas acima são um exemplo limite do que aqui entendemos como a atuação da Pastoral Carcerária no cume do sistema punitivo. Outras iniciativas levadas a cabo pelo Projeto Justiça Cri- 
minal/Brasília e pela Rede Justiça Criminal que ele origina poderiam ser aqui também citadas. Entre elas, a mobilização em favor da Súmula Vinculante 57 - aprovada como súmula vinculante 56 pelo STF no dia 08 de agosto de 2016 - que tem como relator também o Ministro Gilmar Mendes ${ }^{6}$ e visa erradicar o problema de presos que já conquistaram legalmente o regime semiaberto, mas permanecem cumprindo suas penas sob o regime fechado, além da mobilização pelo fim da revista vexatória de familiares e amigos de presos nos dias de visita.

No cume, as supostas grandes decisões são tomadas, aquelas que concernem ao conjunto do sistema prisional brasileiro. Mas o cume também se desdobra em cascata numa miríade de instâncias decisórias hierarquizadas: do STF à sala do diretor de disciplina de uma unidade qualquer. Não há diferença de natureza do que se faz quando se conversa com tomadores de decisão em favor de um ou de vários presos. Entre o advocacy em Brasília e a intervenção pastoral no setor administrativo de uma unidade existe apenas uma diferença de escala. Por isso, os dilemas éticos e políticos que se colocam em uma instância não deixam de estar presentes nas outras. A função analítica que se desdobra desse nível de intervenção é racionalizante, naquele sentido estabelecido por Weber (2004). Frente às autoridades, resta apelar à razão, à racionalidade, à razoabilidade. O discurso analítico se converte num arrazoado: o cárcere não se constitui como o meio mais adequado ao fim de minorar os casos de uso problemático de drogas (Campos, 2015); a negação de um direito conquistado não pode ser o meio mais adequado de promover a reinserção de um

${ }^{6}$ Tese definida no RE 641.320, rel. min. Gilmar Mendes, P. j. 11-5-2016, DJE 159 de 1-8-2016, Tema 423. Disponível em: http://www.stf.jus. br/portal/iurisprudencia/menuSumario.asp?sumula=3352. Acesso 21/07/2018 preso ao mundo livre; a humilhação de um familiar não coaduna com a importância que os vínculos afetivos desempenham na dissuasão da reincidência; se tal preso não for atendido por um médico, ele vai morrer. O discurso que se dirige ao poder apela à razão na sua modulação mais simples e linear: seus meios não promovem os seus fins.

Se esse apelo discursivo à razão constitui-se como a própria maneira de intervir frente às instâncias decisórias, essa dimensão não está ausente quando redigimos um artigo, uma dissertação, uma tese. A universidade, a academia e a ciência também repousam no cume. Em algum momento, no começo ou no final de nossos escritos, somos obrigados a nos posicionar como diante de um tribunal, diante de uma autoridade ou de um público abstratos e apelar à razão: a prisão é perversa, contraproducente, multiplica dores e sofrimentos, tritura corpos e almas, ameaça pessoas, nos coloca a todos em condições precárias. A tensão constitutiva dessa modalidade de discurso/atuação é aquela que se experimenta quando se sabe que as autoridades estão cientes do que estão fazendo, que o fazem deliberada ou burocraticamente, segundo uma racionalidade própria, que o justifica inteiramente e, mesmo assim, não podemos deixar de opor-lhes esse apelo à razão universal e humanística, a mesma que aflorava no exato momento histórico em que a prisão se estabelecia como forma de punição por excelência (Foucault, 1999). Portanto, uma armadilha como o próprio cárcere: uma jaula de ferro.

\section{CONSIDERAÇÕES FINAIS}

Finalizamos o exercício reflexivo lembrando que aqui não dispomos mais do que notas, apontamentos, (auto)provocações. Quere- 
mos enfatizar que, ao mobilizarmos a metáfora geológica, não pretendemos reificar uma figuração verticalizada do Estado e da prisão. Com efeito, antes tratamos de iluminar como essas verticalizações se impõem (Ferguson e Gupta, 2002). Também fazemos questão de colocar em relevo o caráter plural de cada um desses níveis; os subterrâneos, as superfícies e os cumes são sempre múltiplos. Mas, sobretudo, queremos esclarecer que todos eles estão sempre na superfície de nosso mundo. A despeito de nossa metáfora, só há superfície e por toda parte a questão é sempre saber das aberturas e fechamentos que se colocam. Ressalta-se que tais considerações não constituem um exercício meramente egoico, ainda que coletivo. Ao refletir sobre as implicações entre política e cognição, entre pesquisa e intervenção, estabelecemos diálogo com outros autores que, envolvidos com outros temas mais ou menos distantes do nosso, também suscitam a mesma ordem de questões (Malvasi et al., 2018; Moraes et al., 2017).

Concluímos com breves apontamentos que nos parecem imprescindiveis:

1) Enquanto pesquisador, agente pastoral ou militante (e nenhum desses papéis se excluem ou independem um do outro), o contato com a situação agonizante de pessoas presas levanta problemas ético-políticos que atravessam todos aqueles que se posicionam nesse campo de batalha.

2) Hulsman fala da potência e importância da produção acadêmica na desconstrução do léxico punitivo e de seus fundamentos políticos, jurídicos, científicos e filosóficos (Hulsman e Celis, 1993). A universidade não se aparta da mecânica penal e prisional e, enquanto espaço fértil de produção de conhecimento, pode ser um ambiente propí- cio à desmontagem do arcabouço conceitual que justifica a inflição racionalizada do sofrimento como meio de correção de desvios e prevenção de violências.

3) A atuação e pesquisa junto a uma organização como a Pastoral Carcerária nos coloca diante de uma encruzilhada. Se, por um lado, possibilita o exercício de enfrentamentos moleculares e intra-institucionais às dinâmicas penitenciárias quase sempre arbitrárias que fomentam o sistema penal por suas extremidades, por outro, corre-se sempre o risco de converter-se em agente reparador das falhas do sistema. De todo modo, optamos por assumir esse risco, até porque as trocas de ideias e experiências entre agentes pastorais, pesquisadores e aqueles e aquelas que habitam a prisão podem fortalecer política e subjetivamente a todos, contribuindo para a supressão dos punitivismos que habitam cada um de nós.

4) A publicização daquilo que se observa, se escuta e se presencia no interior dos muros como agente pastoral potencializa a luta antiprisional na medida em que escancara a face reprodutora de crueldades e violências assumida pelo cárcere em nossos dias. Longe de cumprir um suposto papel de contenção da delinqüência, a prisão revela-se como instrumento de retroalimentação de conflitos que a extravasam. Publicizar as dinâmicas carcerárias é uma forma de deslegitimar o aparato penal.

5) A Pastoral Carcerária não é a única organização que possibilita atuações nesse sentido e, diante do atual agravamento da situação penitenciária no Brasil, mobilizações antiprisionais têm se proliferado. É com elas que fazemos rizoma.

6) Não se trata de apontar modelos táticos, nem de sedimentar metodologias. Traze- 
mos mais questionamentos do que respostas. Se os cruzamentos entre pesquisa e ativismo na prisão são permeados por um incômodo incessante quando nos questionamos a respeito de nossas próprias práticas, estamos certos de que tomar o cárcere e seus clientes como mero objeto de pesquisa é, no mínimo, oportunismo perverso. Em meio à lógica mercadológica de produtividade e competitividade que marca a academia nos dias de hoje, é capitalizar o sofrimento alheio.

7) Não tratamos, portanto, de mobilizar a Pastoral Carcerária apenas pelo acesso que esta faculta a espaços institucionais cada vez mais inacessíveis, mas de fazer dessa inserção e das atividades desempenhadas - seja a consulta de processos judiciais, seja a realização de oficinas, leituras e debates com os reclusos, seja o encaminhamento de denúncias - uma posição situada e parcial de construção de conhecimento, mas também um ponto de combate em um campo de batalha, no qual as frentes de luta são diversas: desde os embates no campo acadêmico, passando pelas batalhas no âmbito político - descriminalização de todas as drogas, fim do processo de encarceramento massivo, extinção das forças policiais militarizadas - até os combates no coração da própria Pastoral Carcerária em relação a setores mais conservadores.

\section{REFERÊNCIAS}

Agamben, G., \& Assmann, S. (2008). O Que Resta De Auschwitz. São Paulo: Boitempo.

Associação Nacional de Pós-Graduação em Ciências Sociais - ANPOCS. (2011, outubro) "Moção sobre "Ética em Pesquisa" apresentada e aprovada durante a $36^{a}$ Assembléia Geral e Ordinária da Associação Nacional de Pós-Graduação e Pesquisa em Ciências Sociais ANPOCS, realizada no dia 28 de outubro de 2011, na cidade de Caxambu / MG." [online] Recuperado de: http://anpocs.org/index.php/universo/institucional/ mocoes-sp-1243763237/755-mocao-etica-em-pesquisa-28102011 (Acesso em jul. de 2017).

Antunes, S. (2017). Para habitar entre grades: táticas de [sobre]vida na prisão. Aracê - Direitos Humanos em Revista, v.4, n.5, p.116-135. Recuperado em: https:// arace.emnuvens.com.br/arace/article/view/136

Barak-Glantz, I. L. (1981). Toward a conceptual schema of prison management styles. [Para um esquema conceitual de estilos de administração prisional] The prison journal, v. 61, n. 2, p. 42-60. doi: $10.1177 / 003288558106100206$

Biondi, K. (2010) Junto e misturado: uma etnografia do PCC. São Paulo: Terceiro Nome.

Campos, Marcelo da Silveira. (2015). Pela metade: as principais implicações da nova lei de drogas no sistema de justiça criminal em São Paulo (Tese de Doutorado em Sociologia). Faculdade de Filosofia, Letras e Ciências Humanas, Universidade de São Paulo. São Paulo, SP, Brasil.[online] Recuperado de: https://www. teses.usp.br/teses/disponiveis/8/8132/tde-31072015151308/pt-br.php (Acesso em jan. de 2020)

Campos, M. S. \& Valente, R. A. (Outubro, 2012). O julgamento do recurso extraordinário 635.659. Boletim IBCCRIM, pp. 2-4.

Castro e Silva, A. M. (2011). Participo que... Desvelando a punição intramuros. Rio de Janeiro: Publit.

Chantraine, G. (2004a) Par-delà les murs. Trajectoires et expériences en maison d'arrêt. [Para além dos muros : trajetórias e experiências numa casa de detenção] Paris: Presses Universitaires de France-Le Monde. (2004b) Prison and sociological perspective. [Prisão e perspectiva sociológica] Champ Pénal/ Penal Field, v. 1 n. 1. pp. 2-11.

Coelho, E., \& Coelho, M. (2005). A Oficina do Diabo e outros estudos sobre criminalidade. Rio de Janeiro: Record.

Combessie, P. (1996). Prisons des villes et des campagnes: étude d'écologie sociale. [Prisões de cidade e de campo : estudo de ecologia social]. Québec: Les Classiques des Sciences Sociales. doi: 10.1522/030164447 Deleuze, G. (1987). Foucault. Barcelona: Paidós.

DEPEN - Departamento Penitenciário Nacional. (2016) Levantamento Nacional de Informações Penitenciárias. Infopen - Dezembro 2014. Brasília, Ministério da Justiça.

Dias, C. (2013). PCC: hegemonia nas prisões e monopólio da violência. São Paulo: Saraiva.

Diniz, D. (2015). Cadeia: relatos sobre mulheres. Rio de 
Janeiro: Civilização Brasileira.

Fassin, D. (2009). Une science sociale critique peut-elle être utile?. [Um ciência social crítica pode ser útil?] Tracés. Hors-série, p. 199-211.

(2015). L'Ombre du Monde: une anthropologie de la condition carcéral.[A sombra do mundo : uma antropologia da condição carcerária] Paris: Seuil.

Ferguson, J. \& Gupta, A. (2002). Spatializing states: toward an ethnography of neoliberal governmentality. [Espacializando estados: para uma etnografia da governamentalidade neoliberal] American Ethnologist, v. 29, n. 4, pp. 981-1002.

Foucault, M. (1996). A ordem do discurso. São Paulo: Loyola.

(1999). Vigiar e Punir: história da violência nas prisões. Petrópolis: Vozes.

Godoi, R. (2017). Fluxos em Cadeia: as prisões em São Paulo na virada dos tempos. São Paulo: Boitempo.

Haraway, D. (1988). Situated knowledges: the Science question in feminism and the privilegie of partial perspective. [Saberes situados: a questão científica no feminism e o privilégio da perspectiva parcial] Feminist Studies, v. 14, n. 3, pp. 575-599.

Hulsman, L. \& Celis, J. B. (1993) Penas perdidas. O sistema penal em questão. Rio de Janeiro: Luam.

Lago, N. (2014) Mulheres na prisão: entre famílias, batalhas e a vida normal. (Dissertação de Mestrado em Antropologia) - Universidade de São Paulo, SP, Brasil.

Lemgruber, J. \& Paiva, A. (2010). A Dona das Chaves: uma mulher no comando das prisões do Rio de Janeiro. Rio de Janeiro: Record.

Mallart, F. (2014). Cadeias dominadas: a Fundação CASA, suas dinâmicas e as trajetórias de jovens internos. São Paulo: Terceiro Nome.

Malvasi, P., Salla, F., Mallart, F. \& Melo, R. (2018). Saberes da encruzilhada: militância, pesquisa e política no sistema socioeducativo. Etnográfica, v. 22,. n. 1, pp. 76-96.

Massaro, C. (2014). Trabalho em tempos de crise: a superexploração do trabalho penal no Centros de Ressocialização femininos do Estado de São Paulo. (Tese de Doutorado em Ciências Sociais) - Universidade Estadual Paulista, Araraquara, Brasil.

Melo, F. A. (2014). As prisões de São Paulo: Estado e mundo do crime na gestão da 'reintegração social'. São Paulo: Alameda.

Minhoto, L. (2015). Foucault e o ponto cego na análise da guinada punitiva contemporânea. Lua Nova, n. 95, pp. 289311.

Moraes, A., Parra, H., Albuquerque, H., Tible, J. \& Schavelzon,
S. (2017). Quer dizer, então, que a periferia é liberal? [online] Disponível em: http://outraspalavras.net/brasil/quer-dizer-entao-que-a-periferia-e-liberal/ (Acesso em jul. de 2017). Ministério da Saúde. (2016). Resolução n. 510 de 7 de abril de 2016. [online] Disponível em: http://conselho.saude.gov. br/resolucoes/2016/Reso510.pdf (Acesso em jul. de 2017). (2017). Plataforma Brasil. [online] Disponível em: http://aplicacao.saude.gov.br/plataformabrasil/login.jsf (Acesso em jul. de 2017)

Ramalho, J. R. (2002). O mundo do crime: a ordem pelo avesso. São Paulo: IBCCrim.

Reiter, B. (2017). Theory and Methodology of Exploratory Social Science Research. [Teoria e metodologia da pesquisa exploratória em ciências sociais] International Journal os Science and Research Methodology, v.5, n.4, p. 129-150.

Ricordeau, G. (2007) Les relations familiales a l'epreuve de l'incarceration: solidarités et sentiments à l'ombre des murs. [As relações familiares à prova do encarceramento : solidariedades e sentimentos à sombra dos muros] (Tese de Doutorado em Sociologia) - Université Paris IV - Sorbonne, Paris, França.

Rothman, D. J. (2008). The Discovery of Asylum: social order and disorder in the New Republic. [A descoberta do Asylum: ordem e desordem social na Nova República] London: Aldine Transaction.

SAP - Secretaria da Administração Penitenciária. (2017). Comitê de ética em pesquisa da SAP. [online] Disponível em: http://mww.sap.sp.gov.br/comite-etica.html (Acesso em jul. de 2017).

Senellart, M. (2006). As artes de governar. São Paulo: 34.

Stebbins, R. (2001). Exploratory Research in the Social Sciences. [Pesquisa exploratória em ciências sociais] Thousand Oaks: SAGE.

Zamboni, M. (2017). "O barraco das monas na cadeia dos coisas: notas etnográficas sobre a diversidade sexual e de gênero no sistema penitenciário." Aracê - Direitos Humanos em Revista, v.4, n.5, p. 93-115.

VÁRIAS ORGANIZAÇÕES. (2014). Agenda nacional pelo desencarceramento. [online] Disponível em: http://carceraria. org.br/agenda-pelo-desencarceramento.html (Acesso em jul. 2017).

Weber, M. (2004). Economia e Sociedade: fundamentos de sociologia compreensiva, v. 1. São Paulo: UNB/Imprensa Oficial.

Data de submissão: 30/07/2018

Data de aceite: 17/06/2019 